\section{LA CIUDADANÍA COMO ÁMBITO DE INTEGRACIÓN SOCIAL ANTE EL FENÓMENO DE LAS MIGRACIONES}

\author{
Cristina Santamarina \\ Cimop (Madrid)
}

\begin{abstract}
One can only begin to understand immigration through conflict with others, with that which is different and, therefore, as a complex experience for all cultures. We cannot expect these conflicts to be resolved in the uncertain sphere of society or transfer them to the administration. Citizens form the only institution truly capable of accommodating this new reality striking down like a new challenge for European societies. That is because we, the citizens, accept the rights and duties inherent to our institution, and we can even extend this proposal to other peoples, to peoples with their own baggage, cultures and experiences given they are willing to assume these same rights and duties.
\end{abstract}

KEY WORDS: Citizen form; migrations; membership; freedom; incumbency; rights; duties.

... fundar un lugar seguro para la libertad (Hannah Arendt)

Hace unos años, un amigo me contó el siguiente chiste: un padre y un hijo judíos están en Sydney y el padre le dice al hijo: verás, Aaron, todos éstos que ves aquí son gentiles, tú y yo somos judíos. Unos años más tarde están en Nueva York y le dice: ves Aaron, todos estos hombres y mujeres que están aquí son gentiles; tu y yo somos judíos. Tiempo después están otra vez juntos en Madrid y vuelve a decirle: todos éstos que ves aquí, hijo mío, son gentiles, tú y yo somos judíos. Hasta que, finalmente, el hijo, después de éstos y otros viajes con similares resultados, reflexiona en voz alta ante su interlocutor: que pena los gentiles, padre, tan dispersos por el mundo...

La peculiaridad de la experiencia humana -sea cual seaimplica siempre una complejidad que, por principio, descentra las supuestas verdades objetivas y construye más sentidos de los esperados y más representaciones operativas que verdades absolutas ¿Qué papel juega la representación

\section{CITIZENSHIP AS A PLACE FOR SOCIAL INTEGRATION OF MIGRATION PROCESSES}

RESUMEN: El impacto de la inmigración no puede comprenderse más que desde el conflicto del encuentro con los otros, con lo otro diferente $y$, por tanto, como experiencia compleja para toda cultura. No podemos tampoco esperar que esos conflictos se resuelvan en el incierto espacio de lo social ni transferir a las administraciones esta responsabilidad. La institución de la ciudadanía es la única con capacidad verdadera para acoger esta nueva realidad que golpea como un nuevo desafío a las sociedades de Europa. Porque la ciudadanía es la institución en la que aceptamos los derechos y los deberes de la pertenencia y desde la cual es posible ampliar dicha propuesta a otros, con otros bagajes, culturas y experiencias, que estén dispuestos a asumir con nosotros, esos mismos derechos y deberes.

PALABRAS CLAVE: Ciudadanía; migraciones; pertenencia; libertad; incumbencia; derechos; deberes.

social de uno mismo y de los otros en el contexto de una identidad personal? ¿Y qué papel juegan en la constitución de los imaginarios colectivos las representaciones que forman el nosotros para diferenciarlo de los otros en la constitución política de la ciudadanía? Me refiero tanto a las representaciones psicosociales como a la representatividad de los diferentes sujetos y grupos; tanto aquellas representaciones que sustentan el sentimiento de pertenencia o de distancia crítica respecto de la propia cultura o sociedad como a la idea/imagen/discurso que define a los grupos para sí y para los otros. Estoy pensando, lógicamente, en las diferencias que estructuran la noción de ciudadanos y por tanto de identidades tanto nacionales como de otro tipo, frente a conceptos tan escurridizos como son extranjeros, emigrantes, inmigrantes, diferentes... en suma, identidades supuestamente carentes de derechos y exentas de deberes, aquéllos, en definitiva, que representan lo otro social en España, en Europa o en cualquier lugar del mundo.

Cabe una primera observación general: la antigua rejilla categorial que asignaba un lugar fijo y estable a las di- 
versas realidades, situaciones y sujetos determinándolos a ser tales, habrá de considerarse ahora como una complejísima trama que los sobredetermina. Y los sobredetermina porque en el discurso de las realidades históricas es muy difícil encontrar una única respuesta ante problemas irreductiblemente complejos, como son en sí mismos la sociedad, la ciudadanía, la migración, tres entidades complejas, autónomas en su consideración, pero intrincadas irremediablemente, que, sin embargo, la realidad misma nos exige poner en juego. Las ciencias sociales importaron el concepto "sobredeterminación" del psicoanálisis freudiano ya que fue el mismo Freud (1981) quien acuñó el término para explicar que cada elemento del sueño podía remitir a diferentes causas y, a su vez, una misma causa podía estar representada por varios elementos. La determinación del sueño o del síntoma como las representaciones socio-culturales, las identidades institucionales como la ciudadanía o los fenómenos sociales como la migración, o la entidad siempre destotalizada que es lo social, se comprenden, entonces, por la superposición y la interconexión simbólica de diferentes estratos de significaciones, ninguna de cuyas parcialidades es capaz de explicar el fenómeno en su conjunto. Lejos de proponernos un referente unívoco, todo mecanismo de representación da lugar a diferentes cadenas explicativas que no siempre pueden cerrarse en un concepto estable y, menos aún, único.

Por ejemplo, ¿qué representaciones sostienen en una dimensión no consciente de la cultura y la territorialidad el sentimiento de pertenencia a una comunidad, una tradición, una nación? ¿Es posible mantener la responsabilidad de la incumbencia social sin que intervenga a la par el ejercicio de una distancia crítica respecto de lo propio? ¿Es posible articular una ciudadanía como expresión política de la pertenencia socio-cultural a una serie de particularidades vivenciales, pero al mismo tiempo pensar esa ciudadanía como imperfecta, abierta a la diversidad y cuyo principal sentido de ser reside en que la realidad es siempre conflictiva? ¿Cómo juegan todos estos factores y estratégicas categorías en el siempre abierto y conflictivo tema de la identidad?

Cada cultura retiene del amplio flujo de lo dado, diferentes significaciones que rigen las representaciones simbólicas de todo y del todo: del cuerpo y del alma, de lo visible y lo invisible, de las formas de organizar lo central y los márgenes, lo que corresponde incluir y lo que no puede traspasar fronteras y ha de quedar excluido... Estos signos y sus valores subtienden la pertenencia tanto en sentido positivo como negativo. En el Tratado de la naturaleza humana (lib. III, pars 2), Hume arroja la siguiente figura: "Un inglés en Italia es una amigo. Un europeo lo es en China y quizá querríamos a un hombre, sólo por serlo, si lo encontrásemos en la luna". La cita pone de manifiesto que se trata de un sentimiento sobredeterminado en la medida en que no tiene un referente inamovible sino que va creando su referente de acuerdo a la situación o contexto en el que se experimenta. Pero también interesa rescatar otra enseñanza concomitante: quien no reconoce la primacía de lo social y cultural de la incumbencia, el hecho de que pertenecemos a algo antes de ser algo incurre en una visión falsamente individualista que se halla muy lejos de los implícitos necesarios en la intención comprensiva de estas páginas. 0 dicho en otros términos, frente a la siempre rechazada tendencia a mirarse el ombligo, dado que parece tratarse de una práctica poco frecuente, la misma deviene muy necesaria, si somos capaces de mirar educando el ojo, porque el ombligo, en su expresividad, nos debería recordar que hemos pertenecido a otro (sujetos, tiempo, espacio, relaciones...) antes de ser quienes nos miramos, o quienes somos, o quienes creemos ser. Pero también -y paradójicamente- resulta espuria la identidad de cualquier sujeto que no puede tomar distancia respecto a las formas específicas de su propia pertenencia social, ejerciendo la libertad de juzgarla e incluso, llegado el caso, enfrentarse a sus exigencias o propuestas. Inmensa y siempre inacabada, la tarea interpretativa significa atreverse a hacer un contexto para cada texto y dotarlo de cierta capacidad lógica explicativa que en ningún caso es justificación y que deberá sostenerse en este extraño equilibrio entre pertenencia y derecho a la diferencia cuando se piensa de manera explícita cualquier dimensión relacional identitaria y, más aún, cuando se piensa la identidad desde y con, las circunstancias migratorias.

\section{LA MIGRACIÓN COMO REALIDAD PARADÓJICA}

Nortrop Frye (1986) propone pensar lo social como el combate de dos grandes agrupamientos de mitos: los mitos de pertenencia, propios de toda sociedad, verdaderos universales a pesar de las profundas diversidades existentes y en los que se expresan las creencias básicas que nacen como 
respuestas a ciertas cuestiones cruciales como la existencia, la unidad y la continuidad de una comunidad y que podrían condensarse en una sola y compleja pregunta: ¿qué debemos ser y hacer para salvarnos? La verdad y la realidad consideradas desde los mitos de pertenencia no responden al examen del saber y el conocimiento razonados, sino que se articulan como saberes de creencia, esto es, considerar verdad aquello en lo que se cree y esta creencia es, finalmente, la adhesión a un determinado mito. Socializarse implica necesariamente un a priori: mirar, sentir, aprender de acuerdo a parámetros no ontológicos, sino históricos y culturales propios de la sociedad a la que se pertenece. Lo primario es la pertenencia (pertenecemos a algo antes de ser algo). Reconocer este principio regulador no pretende banalizar las instituciones de referencia-sociedad, ciudadanía, migración- sino, por el contrario, situarlas en la encrucijada de su frágil complejidad instituyente y articuladora.

Comenzaré con un ejemplo experiencia para ilustrar mi perspectiva: Hace varios años, un manchego de Albacete -entonces tierra pobre entre las pobres-, emigrado primero a Barcelona y luego a Hamburgo cuando los años de la migración española, resumió un día de este modo sus impresiones de migrante: "Verá usted -me dijo- todo es distinto en el norte: el clima, la comida, las casas, la gente, la lengua... A mi llegada yo pensaba que todos debían ser iguales a nosotros. Después entendí que eran ellos quienes estaban en su casa y era yo quien debía esforzarme por comprenderlos, entendí que tenían derecho a la diferencia".

Huelgan los comentarios sobre las distancias recorridas por este hombre. No tanto distancias exteriores sino interiores, recorridos inconmensurables, verdaderas migraciones internas. Lo enseñaba su excéntrica actitud de otorgar, señorialmente, a los hamburgueses, desde una situación de minusvalía socio-cultural -propia de ciertas etapas de la migración-, el derecho a la diferencia. Por encima de toda distancia lingüística y etnológica, su conclusión expresaba una experiencia acorde con la altiva divisa de sus huéspedes obligados, aquélla que figura en el escudo de la Liga Hanseática y que dice: Navegar es necesario, vivir no. En la parquedad de tal consigna cabe una verdad que atañe a la sustancia de la experiencia migratoria: el que deja su tierra es un navegante forzado, que ha de atender por largo plazo a la exigencia del navegar por encima de la de vivir.
Porque vivir significa, para el migrante, tomar conciencia estremecida de una navegación que ha cambiado de rumbo, significa resituarse respecto a los puntos cardinales de su propia cultura - poder pensarla como tal, como cultura y como propia pero no como verdad única- y situar los de la ajena. El discurso de aquel interlocutor manchego depuraba así el sentido más íntimo de esa experiencia -sometida, por muchos motivos-, al doble condicionamiento del desarraigo y de la mirada meridional respecto al norte, la misma que hoy desde otras latitudes construye las metáforas de los opuestos asimétricos: subdesarrollo frente a mundo desarrollado, pobres frente a ricos, periféricos frente a centrales, incluso -por absurdas vueltas de la historia-, América frente a Europa. Enfrentamiento de opuestos, finalmente, de mundos irreconciliables, de necesarias distancias para sustentar cierta idea de un nosotros en común, o más aún, de potencial comunidad que la misma historia, finalmente, se encarga siempre de desbaratar. Metáfora de metáforas, a ello ha contribuido de forma notable tanto la importancia del expresionismo de los opuestos como el amplio, diverso y complejo magma de producciones culturales -y vivenciales, como no- que ha generado. Por ello nos es tan cercano como término y tan temida como experiencia. Porque lo hemos visto, lo hemos oído, lo hemos leído pero, sobre todo, la historia de España lo ha vivido de uno y otro lado: hemos sido un país que expulsó a sus hijos tras sus fronteras y que hoy recibe impávido la llegada de otros, mejor o peor recibidos, pero siempre como diferentes.

\section{LO OTRO, LOS OTROS COMO EXPERIENCIA}

Todo extrañamiento implica un penoso aprendizaje que podría resumirse así: el mundo se vuelve doblemente ajeno, y esto duele, pero cabe admitir que también se muestra ancho, y esto invita a considerar los horizontes de fuera, anchos y ajenos, sin ninguna duda, como una invitación para dilatar los de dentro. Bajo tal enfoque, el peor contexto, el más enajenante, puede ofrecer un buen pretexto para ampliar la visión, sea porque vemos más a lo lejos o más de cerca, porque miramos las cosas desde arriba o porque las padecemos desde abajo, porque nos obliga a cambiar la perspectiva y a cuestionar la contumaz transparencia de lo obvio, de lo que creíamos ver de frente y sin dobleces, lo que pensamos que era común a todas las culturas y no 
peculiar e intransferible, lo que lleva, por sobre todas las cosas, a pensarse como parte de una comunidad $-y$ hoy por nombrar el caso más frecuente-, la que corresponde a las identidades nacionales, pero fundida hasta entonces, más que confundida, con la fantasía de una realidad universal. Y resulta que no, que toda cultura de la que venimos es particular y nada generalizable en infinidad de signos y significantes $y$, más aún, que ese amplio horizonte de particularidades culturales a las que pertenecemos, jamás habian sido motivo de reparo para los viajeros de esta nave cuyo primer sentido, cuyo primer destino será, sin ninguna duda, el que corresponde al incierto puerto de lo distinto, lo desconocido, lo diferente, lo incierto, lo despreciable, lo no querido, lo incorrecto, lo otro. Nadie se reconoce en su identidad nacional, local, regional hasta que no padece el enfrentamiento con lo diferente, hasta que no se experimenta el afuera, la ausencia de domus, la pérdida de la socialización que no sólo está en lo visible, sino fundamentalmente en lo invisible: en los sabores, en los olores, en los colores, en los temores y en los amores. Dicho de manera sintética, nadie se piensa como peruano, vietnamita o finlandés hasta que no está fuera de Perú, Vietnam o Finlandia. Esta experiencia contradictoria, doliente en su estructura, de simultáneo distanciamiento y descubrimiento, de apertura y de cierre, es difícil de vivir, pero dicha vivencia cobra alguna semántica sólo cuando logra ser narrada: "... no hay dolor que no quepa en un relato" (Char, 1984). Y por su parte, Goethe (1999) nos enseñó que "... un dios nos concedió decir para saber que estamos vivos".

Por traumática e irreversible, se trata de una experiencia de la incompletud y de división del sujeto como marca irrenunciable de la misma biografía personal que, siendo un fenómeno siempre colectivo, se vive desde la peculiaridad de lo experiencial abriendo a diferentes reflexiones, de las cuales, la más definitiva es que la migración ha de servir para algo más, para mucho más que para sufrir. Como en el caso del manchego al que aludi, se alcanza una figura compensatoria: la defensa de un nuevo derecho -el derecho a la diferencia- reclamado y otorgado para tipificar un viejo delito, un viejo reflejo condicionado de los grupos, los pueblos y las culturas: el rechazo de todo cuerpo extraño, ejercido tanto por los anfitriones como por los recién llegados. Los "diferentes" que han asimilado la experiencia de la migración, de la marginación o de la persecución -llámense disidentes, desterrados interiores o exteriores, homosexuales, periféricos en la metrópoli o metropolitanos en la periferia- asumen con otra perspectiva, diferente a los iguales en la norma, los balances de dicha experiencia. Norma y pertenencia podrán a ser entonces -es más, deberán serlo más tarde o más temprano- objetos de revisión.

Una comunidad es tanto más fuerte cuantas más diferencias es capaz de albergar sin necesidad de reprimir y cuanta mayor diversidad es capaz de contener en su amplia panoplia de narraciones identitarias. Un sujeto es tanto más persona cuantos más "otros" reconoce dentro y fuera de sí. Por poner un ejemplo muy conocido en España, podemos afirmar que cuanto más estrecho el nacionalismo, más mezquinas y peligrosas sus consecuencias. Cuanto más cerrado el sujeto más estrecho su mundo. Cuanto más abierta la noción de Nación y menos idénticas las personas, más universal sus diferencias y más firme su identidad. Si esto que afirmo es cierto, podriamos convenir, casi por deducción, que una nueva forma de identidades mixturadas se está gestando en nuestras tierras, estas mismas tierras en las que cada vez más las estrecheces de miras son parte del discurso sobre la realidad en cualquiera de sus formas de acercamiento.

Para que una cultura pueda abrirse a un horizonte estratégico de comprensiones narrativas -se lo proponga o no- ha de ensanchar sus condiciones de ejercicio, o sea, arriesgar la apertura de sus propios límites. Cuando la diferencia se vuelve creadora de valores, su fuerza social puede enfrentarse a cualquiera de las éticas más asentadas. Y para liberar a la imaginación y que cada propuesta no quede tan sólo como una repetición en el rosario de las cuentas infelices, hay que propiciar las miradas interpretadoras respecto a las normas propias y ajenas. Habrá que "ponerse en el lugar del otro". Ardua tarea que implica el proceloso trabajo de identificarse con el otro tanto como desidentificarse con esos mismos, al menos, con las muchas figuras reconocidas y presentadas como propuestas identificatorias colectivas. Esto es fácil de decir y muy difícil de hacer. No se trata siempre de presentar a héroes de folletín, sino a personajes de una gran complejidad situados en el centro de situaciones dilemáticas tanto desde el punto de vista cultural como sobre todo moral y relacional. Culturas enteras, pueblos e individuos prefieren, la mayoría de las veces, acallar la diferencia -y rechazarla en el espejo del otro- para dejarse acoger por la estrecha, aunque protectora identidad de la norma. "Ponerse en el lugar del otro" 
significa entonces desolidarizarse con lo establecido como centro -cultural, social o individual- para comprender, imaginariamente, qué le está sucediendo a alguien que siente y piensa de forma diferente incluso, enfrentándose a los prejuicios que se antepongan en nuestra mirada. $Y$ esto es lo que será necesario tener en cuenta para pensar el derecho a la construcción de una identidad peculiar aún dentro de la condición migrante.

\section{UN SUJETO FUERA DE LUGAR}

Lo natural es ser de donde se ha nacido o mimetizarte con el sitio en el que se está: pasar por blanco aunque se sea negro, hasta que ese diferente, lo descubran. En realidad, quien está en el lugar de donde es, de lo propio, el lugar de la incuestionable pertenencia es más. Es el modelo original. El de fuera, el otro, por más integrado que esté, es apenas una versión subtitulada. Mexicano en Chicago, sudaca en Madrid..., infinidad de mixturas lo avalan... El que es de fuera, entiende; pero menos: invisibles cadenas asociativas le amarran a otras historias y hacen que yerre en la metáfora. Así es percibido. El que es excepcional vive comparando porque se socializa siendo comparado. Fija residencia en el metalenguaje. Pues, para dejar de ser incorrecto, debe tenerlo todo en cuenta, debe saber integrar hasta el sueño. El modelo, el que es del lugar -en cambio- no compara: excluye. Natural y legítimamente. Olvida, omite, no tiene en cuenta ser incorrecto. No le importa equivocarse. Al inmigrante sí, cualquier detalle delatará su diferencia. Los que son del territorio, comen lo que hay que comer. Hablan como es debido. El de fuera es un error de ortografía. Padece complejo de dialecto. Los del lugar hablan de corrido. El otro, en cambio, antes de hablar, ha de pensar en las palabras. Compararlas. Elegirlas. Para eludir el tedioso inciso siempre revivido "¿tú-dedónde-eres?" Pero también está la piel como delatora de la diferencia, sobre todo en países como los europeos que durante muchos siglos separó continencias por epidermis. Parece inevitable: lo excepcional no es un individuo, es un género. No reconocido en su individualidad, sino como una muestra, como parte de algo que es extraño. Ejemplo de algo que de allí, no es. Un espécimen de lo otro. Y ser lo otro significa, básicamente, no ser uno. Por eso la importancia de pensar las identidades migratorias como derecho a nuevas identidades desterritorializadas emerge como un compromiso que lo social en su vaguedad incorpora después de muchas resistencias, después de muchos errores. De allí que corresponda a la institución de la ciudadanía -y sólo a ella en todas sus formas de expresión- la complejidad de esta tarea.

Decía Bertolt Brecht (1978) en un ya emblemático poema del desarraigo: "Me parezco a aquel hombre que andaba por el mundo con un ladrillo, tratando de explicarle a todos como era su casa". El otro, el de fuera no sólo es diferente sino que apenas balbucea a los del lugar lo que quiere decir de sí, más allá de la expresividad -mayor o menor-que ponga en juego.

Por su parte, la masa de los propios del lugar, practican como anfitriones la actitud de la indiferencia. La in-diferencia es un modo tajante y radical de incomunicación, el único modo que excluye todo ejercicio de imaginación hacia lo distinto, aquello que impide "ponerse en el lugar del otro" por falta de interés y de estímulo. Ser indiferente es, justamente, haber perdido la sensibilidad para las diferencias, para las de afuera, pero también para las de adentro y conseguir que la insensibilidad alcance al mismo ejercicio narrativo: no hay nada que decir, no hay opinión al respecto, no hay argumento, no tiene ninguna importancia, el otro no es más que una circunstancia, lo otro no se tiene en cuenta... Casi mejor el discurso reaccionario de quien está en contra, quien persigue, porque éste -a su manera- reconoce. Mientras que el indiferente acaba condenando al migrante a una no identidad que lo condena a la invisibilidad en todos los órdenes: como género de lo distinto, como peculiaridad en proceso, como humano no definitivo, como alguien que tal vez, con viento a favor, algún día deje de navegar (entre dos aguas) y pueda comenzar a ser. Por el contrario, es bajo el signo de una concatenación de diferencias estructurales que podemos pensar uno de los marcos narrativos más interesantes del complejo problema de la migración y la identidad, la de los antagónicos emocionales que se construyen sobre ejes cartesianos no reales, sino imaginarios y simbólicos.

Tal es la responsabilidad de la institución ciudadana y el ejercicio necesario para alcanzar en sus objetivos a todos, no sólo a los que llegan sino a sus mismos aborígenes. Porque la institución ciudadanía más que un título otorgado es una conquista desde lo social que acepta sus divisiones en tanto necesarias e intrínsecas a todo devenir social 
pero que propone al mismo tiempo un foro de pertenencia para desde allí construir el vínculo con los demás, sean reconocidos como propios (partidarios, fratría, etnia, raza... propios), o no, es decir, la impertinente intromisión de lo otro (adversarios... en cualquiera de sus manifestaciones). Porque se trata de la instancia creada en democracia más abierta a la pertenencia que parece existir a condición de que le reconozcamos, a un mismo tiempo, pertenencia por derechos y por deberes. Una sociedad que destruye su libertad, dice Frye (1986), engendra el mundo orweliano de 1984; una sociedad sin sentimiento de pertenencia, sin incumbencia alguna, engendra Un mundo feliz como el de Huxley (1980), donde la indiferencia reniega de la libertad misma porque nada pesa como arraigo y nada importa como compromiso.

\section{LA CIUDADANÍA COMO UMBRAL}

Para avanzar en la consideración de la ciudadanía, demos un paso más desde estos mismos principios pensando una ciudadanía donde opera la tensión fructífera entre pertenencia y distancia, entre incumbencia y libertad. Por seguir con la terminología de Frye (2001), la opción no adopta, no puede adoptar la antigua forma viciada de la alternativa excluyente: una opción o la otra. Por el contrario, lo que rige es la alternativa inclusiva o incluyente: tanto una como la otra aceptando, al mismo tiempo, que en lo social existen diferencias y más aún divisiones, porque ella misma, la división, es constitutiva y estructurante de lo social. Pero la ciudadanía, en tanto expresión política de la democracia y de los Estados organizados, exige comprender esta misma institución en tanto articuladora y a la vez resultante de un régimen -tal vez el único en la historia hasta ahora- en que, como sucede en la democracia, la libertad se comparte y se reparte, lo que implica, necesariamente la aceptación del conflicto en su propia definición. Porque si por un lado la democracia se construye sobre una base social estructurada por la división misma y por la consideración de que lo otro, lo diferente, está también presente y lo está de forma amenazante -reconozcámoslo-, el debate perenne al que se enfrenta la responsabilidad ciudadana es el conflicto entre comunidad e inmunidad (cf. Esposito, 2003). Conflicto aporístico, del cual, de manera concluyente e irreversible, no se puede salir. Las democracias están siempre amenazadas y las ciudadanías son su única posibi- lidad de inmunidad, a condición de aceptar que se trata de una auto-inmunidad siempre vulnerable, construida desde una institución no cerrada ni plegada sobre sí misma, a la que no le alcanzan las actas fundacionales para construir su trayectoria histórica y que su única viabilidad de sentido es aceptar su apertura a estar constantemente replanteando su sentido y dirección, enfrentando las amenazas y buscando la manera de integrarlas, respetando sus diferencias, es decir, integrando políticamente, pero sosteniendo los conflictos de las diferencias económicas, sociales, culturales. De esta forma se comprende por qué la institución de la ciudadanía es una institución de la responsabilidad. Porque es la que se encarga de articular las respuestas ante los conflictos históricos que van produciéndose, esos mismos que irrumpen en la convivencialidad cotidiana, entre las herencias de formas de percibirnos, de sabernos, de hacernos discurso -aunque ya sabemos con Arendt (2003) que toda herencia nos llega sin testamentos- y lo Otro, en toda su compleja y amenazante potencialidad. Porque la ciudadanía es la expresión por excelencia de la pluralidad, condición que nos marca a un mismo tiempo, la posibilidad de ser iguales, siendo distintos. Pluralidad en tanto iguales en la diferencia, y diferentes en la igualdad. Pluralidad por tanto, de sujetos únicos. $Y$ aquí podriamos regresar al chiste y comprender que la supuesta simpatía del error del hijo judío no es tal, en la medida en que la identidad personal, al igual que las identidades grupales, es un juego de diferencias con los otros, siempre -de manera irreductible- dentro de una identidad comprendida como construcción narrativa. Pluralidad, finalmente, que presenta -cómo no- su parte de sombras en la fragilidad, la vulnerabilidad del todos, sin dominio de uno. Porque ni siquiera el cuerpo de leyes es el uno incuestionable, irreversible, sino una forma de discernimiento procedimental que queda sujeto a la voluntad de transformación que se consigna en esa misma fragilidad del todos que es la ciudadanía, asumida como espacio paradójico en donde los éxitos (o los fracasos) provisionales no apuntan a la solución global y definitiva de ninguno de sus retos sino a una construcción, más que inacabada, destotalizada como lo es la realidad social en todo tiempo y lugar.

En efecto, salvo en el totalitarismo donde coinciden dramática y totalmente (es decir, brutalmente) sociedad y Estado, lo social está siempre abierto y persiguiendo una definición de su momento y de su identidad (cf. Lefort, 1998). Esta realidad no debería inducir a la inacción, al 
desencanto o a la conformidad, sino, por el contrario, abrir al compromiso ciudadano que hiciera de esta indefinición un fermento siempre activo en la vinculación entre realidad social y acción política, tan necesaria y esperanzadora para la condición humana.

\section{LA CIUDADANÍA ENTRE LOS DERECHOS Y LOS DEBERES}

Asumir esta apertura inquietante de la condición ciudadana y de su trasfondo social concreto que constituye el eje de responsabilidad pública de todo sujeto maduro abre a un debate que resulta, cuando menos, extraño en nuestras sociedades de la abundancia. Me refiero al debate sobre los deberes, tan oculto debajo de sociedades y culturas que han vivido estos últimos años como sociedades de derechos. Si consideramos el tratamiento otorgado por el discurso de nuestra época al concepto derecho humano, se vuelve manifiesta una franca asimetría con su complementario. En efecto, para un sujeto políticamente concebido a partir de la idea de derecho ¿qué deberes humanos universales supone vivir en un mundo como el presente, globalizado por una parte y profundamente desigual por otra? La idea de derecho, aunque sólo sea como declaración, es relativamente reciente: no tiene más de dos siglos. El concepto de deber, en cambio, es tan viejo como nuestra cultura, nunca fue declarado porque ha estado en la base de los más antiguos mitos de incumbencia desde el principio de responsabilidad individual, eje de la moral de Occidente, e idea central de deuda y culpa tan hegemónicas en la moral judía y cristiana. El siglo XX, por su parte, se ha encargado con creces de tergiversar el problema. Si la responsabilidad se ha trashumado en culpa, en mala conciencia, la impotencia de una patología del deber centrada en la falsa idealización de los sujetos y de los modelos culturales previos, se ha pervertido en una patología de la felicidad cuyo eje central es la figura modélica del sujeto consumidor como representación por excelencia del derecho omnímodo e irreflexivo, promocionado, promovido, publicitado y expandido por la fuerza mediática como sujeto ideal y deber ser de cada ciudadano. Derecho del deseo, finalmente, entendido no como encuentro del sujeto con sus propias fantasías y realidades posibles sino como cumplimiento de un decálogo programado por y desde el imaginario de la cultura consumista, con acuerdo a los intereses de rentabilización económica de las em- presas como agentes hegemónicos de lo real. Así es como confluyen, muy lejos de las expectativas que el siglo XVIII dio a la idea de ciudadanía, un sujeto sin fronteras en el mundo que reclama su derecho a consumir porque éste es el deber por excelencia de la lógica social dominante. Para más inri, esta idea del deber es explotada por las ideologías conservadoras, nacionalistas o ultraliberales según la cual los derechos conseguidos a lo largo de la historia se vuelven para la masa ciudadana -y más aún para la que aspira a serlo en algún lugar del mundo- derechos concedidos ya ni siquiera por los Estados como entidad simbólica sino por las Administraciones que se erigen en poseedoras de la capacidad concededora de identidades por excelencia. La ciudadanía, de esta forma, se sustenta, de manera aplastante para cualquier sujeto, en una forma de responsabilidad individual por la que el individuo -ya ni siquiera sujeto- debe, en la misma proporción en la que se le otorga. Pertenece a lo social en la medida en que recibe y paga -de alguna manera pero sobre todo económicamente- aquello que recibe. Lógica del ciudadano individual, del ciudadano cliente ante la administración que reclama el otorgamiento de derechos en la medida en que paga (compra, adquiere) las prebendas de dicha condición. Quienes no pueden acceder al mercado quedan fuera de lo social y por supuesto de la participación ciudadana real (además de quedar fuera de la alimentación, del acceso a las energías, la posibilidad de beber agua potable, desarrollar proyectos...). Los pobres son extranjeros de esta humanidad cuya identidad protosustancial más elocuente es la de ser consumidores atemorizados ante la amenaza de perder identidad si no cumplen su cometido. La importancia estratégica de pensar de una forma nueva la condición y potencialidad de la ciudadanía urge, como única herramienta de apertura ante un futuro que no esté signado por los fracasos del pasado. Pero, para ello, será necesario revisar los postulados desde los cuales pensamos nuestras instituciones y especialmente la idea de ciudadanía. Difícilmente percibimos la condición de ciudadanía como una forma de lazo social debajo del cual opera un sujeto de la conciencia política, de la conciencia moral, de la subordinación satisfecha a la ordenación jurídica. La sospecha de que ninguno de estos atributos es importante en la construcción de lo social, se ha instalado entre los ciudadanos mismos y dudamos -incluso- hasta de la capacidad de nuestros semejantes para orientar el sentido de su participación democrática, el juicio para la elección racional de candidatos, la lógica igualitaria de la justicia, el

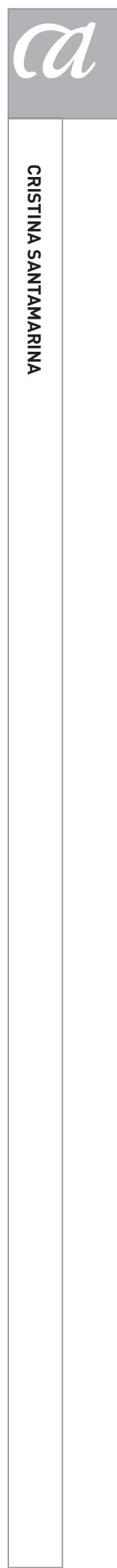


valor diferencial de un documento de identidad acreditativo de la confianza que la Nación-Estado deposita en una persona. De hecho, en nuestras culturas, un documento de identidad tiene menos valía que una tarjeta de crédito.

Por su parte el Estado ya no parece definirse como Nacional si nacional es la concordancia ciudadana con formas específicas de la cultura peculiar, sino más bien como mecanismos técnico-administrativos de control y de gestión, incluso técnico-burocráticos, ante los cuales habrá de subordinarse el conjunto de la población. La legitimación social y política del Estado ya no proviene de su anclaje histórico, de su capacidad para mediar y hacer converger en intereses generales las demandas y expectativas de diferentes sectores sociales, sino de su mayor o menor eficacia en los cometidos sobre los que debe operar, los cuales habrán de ser desarrollados con lógica de gran empresa: organizados desde las propuestas del marketing (ya sea político, social, etc.), presentados con el mismo esquema comunicacional con el que se publicitan los refrescos y los detergentes, utilizando los mismos soportes mediáticos que aquéllos $y$, finalmente, capitaneados por la figura del político empresario (o el empresario político) que tiene en diferentes representantes -Berlusconi como gran paradigma-, su expresión más acabada y sonriente.

\section{Ciudadanía para poder Seguir estando Juntos}

Y resulta que en la actualidad esta idea de Estado ya no es, tampoco ella, un marco apropiado para el desarrollo del capitalismo en la era de la economía global, de lo que da cuentas con creces la actual crisis financiera y ya, como no podía ser de otra forma, económica y social. Porque un Estado Nación pretendía ser la coincidencia de una identidad social -más o menos laxa- con una realidad de mercado interno o nacional. Pero el mercado ha desbordado totalmente las fronteras nacionales (la aparición de los macroestados es más que un síntoma) tras la búsqueda, tal vez desesperada, por lograr formas capaces de conjugar verbos de sentido opuesto. El Estado Nación que operó hasta mediados del siglo XX como una ficción orientativa de la identidad del vínculo social y soporte geográfico de la ciudadanía, ha dejado de ser operativa porque la reproducción ampliada del capital desborda la supuesta sustancialidad de las fronteras nacio- nales. Un síntoma muy claro de que esto sucede, no sólo en la realidad contextual que vivimos sino en la conciencia de los sujetos mismos, es que cada vez más se percibe el carácter inventado de las identidades nacionales, la invención de esos mismos valores que antes se vivían como naturales e incuestionables, síntoma de la falta de credibilidad creciente en las instituciones políticas y en las simbologías a ellas asociadas. $Y$ esto no sucede en el interior de ninguna institución cuando ésta es capaz de actuar como un atractor verdadero, sino desde la descomposición de sus facultades operativas. Por ello el ciudadano se debilita como soporte subjetivo de los Estados actuales, dado que la eficacia desde la que se respeta la integridad administrativa de un Estado no lo es porque exista en función de la ciudadanía, sino en función de una nueva entidad que ha venido a reemplazar a aquélla: los individuos consumidores, consumidores incluso de puestos de trabajo (cf. Alonso, 1999). Asistimos, por tanto, a la mutación del estatuto moderno de sujeto, ya no más ciudadano, sino ahora consumidor, por lo que no parece exagerado anunciar dos grandes cambios intangibles de las sociedades modernas: la de los ciudadanos y la del Estado Nación como representación de los lazos operantes que dieron consistencia identitaria a las sociedades políticas surgidas a partir del siglo XVIII. Pero si esto sucede en el seno de los ya añejos Estados nacionales, cuanto más en lo que respecta a la mirada hacia los inmigrantes recién llegados: de ellos poco o nada se sabe de sus pertenencias nacionales por lo que inmediatamente son trasmutados en negratas, sudamericanos, del este... como únicas categorías de marcos referenciales. Si el Estado aquí es poco fiable, cuanto menos estos nuevos y desconocidos desde los que afluyen.

Se modifica también la noción de vínculo social. La relación de lazos ya no es entre ciudadanos que comparten un proyecto y una historia (una conciencia de antecedente común aunque medien consideraciones diferentes y hasta enfrentadas sobre ella) sino entre consumidores que intercambian signos de representación de su lugar en el campo heteróclito de la escala social que propicia la culturad del consumo. Y se modifica también el viejo concepto de representación en tanto representación política de una identidad sobre la que ha de asentarse la cohesión social para ser reemplazada por la representación de la imagen, construcción ficticia de formas de ser y de hacer en el tiempo de las instantáneas, nuevo tiempo social que, como señala Miguel Marinas (2004), es el tiempo que ya se anticipaba hace un siglo, en los inicios del siglo $X X$, 
como tiempo necesario de la lógica del consumo y que ha tomado forma articulante un siglo después.

La nueva realidad de la globalización lo es también para las posibilidades interpretativas de lo social: ya no es más la historia el fundamento de las formas de ser y de hacer de los pueblos, sino la emergencia siempre cambiante de las necesidades del mercado, que no son las necesidades de las personas, ni tampoco los deseos de los consumidores, son las necesidades del propio mercado. Lógica del beneficio que opera como motor de un sistema que, después de años de narcisismo triunfante, ha tenido que demandar a las instituciones públicas y al sostén de lo público la ayuda para mantenerse en su hegemonía.

La pantalla del ordenador como nuevas formas de construcción de identidades y de vínculos, el famoseo o celebrity como nueva forma de movilidad social efímera sosteniendo a la ya insostenible pantalla del televisor, hacen redundante que si la plaza pública ha sido ocupada por el mercadillo es porque el espacio cívico más atrayente son los nuevos centros comerciales, nuevos templos de la capacidad alucinatoria de la cultura en que vivimos.

\section{A MODO DE REFLEXIÓN}

La soberanía, la ciudadanía, la cultura civil, la cohesión social, el pluralismo ideológico, las convicciones democráticas, las prácticas participativas en las formas de construcción de la sociedad, la confianza en el para qué del desarrollo de la cultura, la finalidad de las comunicaciones, la inserción en lo múltiple como forma de construcción de la identidad, la vía de lo social como referencia del bien general, la defensa de lo público como estrategia de construcción de lo propio, la búsqueda del bien común... aspectos todos ellos que tienden a desdibujarse en el magma de los temores que nos recluyen en la apatía de lo propio, lo privado, la salida individual frente a los grandes temas, la evasión como único mecanismo de permanencia en este mundo que habitamos. El vacio, en definitiva, hace su presencia en la precariedad de la identidad del sujeto pero también en el seno de lo social.

Frente a lo que podria convertirse en un desánimo ante el sin sentido, parece necesario recuperar la paradoja para entender que este vacío inaugura la indeterminación de lo que podemos ser, dar cuenta de lo social y de lo político como espacios y tiempos abiertos. Ni el poder ni el saber se hallan clausurados en ningún ámbito en particular. La democracia es una forma de sociedad y no un mero sistema político. La historia de la representación del poder revela un desplazamiento progresivo de su lugar: el poder era representado primero en la figura del rey que concentraba en su mismidad representacional el poder pero también el saber y la ley. Lo específico de la puesta en forma de la democracia como modo de acceso a lo político consiste en que representa el poder como un lugar vacío. Un lugar expresado en un discurso que dice: "el poder no pertenece a nadie, quienes lo ejercen no lo poseen, tampoco lo encarnan aunque lo sostengan temporalmente" (Lefort, 1997). Desde este punto de vista, la democracia como forma política mantiene la distancia entre lo simbólico y lo real. Pero hay también una segunda distancia o vacío en donde se sostiene la democracia y que es, justamente, la distancia entre sociedad y poder, entre la sociedad civil y la política. Si no se opera esa distancia, estamos muy lejos de la democracia y sólo gobierna el marco del totalitarismo en el que no cabe diferencia, ni discrepancia, ni disenso, ni lo distinto o lo otro. La democracia se instituye y sostiene por esta disolución de la certeza: se inaugura una historia en donde la sociedad experimenta una indeterminación fundamental respecto a las bases del poder, de la ley y del saber en las que deben fundarse nuevas relaciones en cada uno de los niveles de la vida social. Como contrapartida a esa misma incertidumbre ha de aparecer el sujeto de la ciudad, el sujeto responsable que sabe que lo político ha de ser construido de manera constante, que la ciudadanía es su responsable instancia de sujeción y que a ella han de pertenecer todos aquéllos, propios y ajenos que asuman con responsabilidad (es decir, con capacidad de respuesta) la conciencia de la destotalización de lo social, la amenaza constante de dentro y de fuera en la que vive toda sociedad histórica y, sobre todo, la impronta de la pluralidad como base desde la cual apostar a la política de los adversarios -y no, necesariamente de los enemigos- como único camino dialógico, rizomático y siempre imperfecto, de resolución de los conflictos. Esta instancia, la ciudadanía, adquiere su mayor sentido de existencia cuando está en juego la sombra, ¿por qué no decirlo?, amenazante, de la inmigración como escenificación cabal de las diferencias o, más complejo aún, las diferencias de otros con otras potencialidades y otras limitaciones que nos exigen ampliar

ARBOR CLXXXVI 744 julio-agosto [2010] 605-614 ISSN: 0210-1963 
nuestros horizontes de convención y de comprensión de la realidad. Otros que traerán a un tiempo sus conflictos, sus pasiones, sus formas imperfectas de civilidad para exigirnos un constante reformateo de la noción de convivencia y participación, solidaridad y defensa del sentido de libertad. Pero, sin ninguna duda, más que lo social en su laxitud, será desde la comprensión ciudadana, adultez legítima del sujeto de la ciudad desde donde se podrá aceptar la diferencia radical del otro a condición de un pacto según el cual el otro es, como cada ciudadano, sujeto a un tiempo de derechos y deberes.

Vale la pena consignar así una sintesis expresiva de lo dicho, pero que es aún más contundente. Dice Giacommo Marramao (1993): "La democracia -y sólo la democracia- puede llamarse comunidad paradójica, comunidad de los que no tienen comunidad. La democracia está siempre por venir (advenire), porque no sacrifica jamás a la utopía de una transparencia absoluta la opacidad de la fricción y del conflicto, se nutre de aquella pasión del desencanto que mantiene unidos, en una tensión irresoluble, el rigor de la forma y la disponibilidad para acoger huéspedes inesperados. Tal es el cometido de la ciudadanía".

Dado que comencé con un chiste quisiera terminar el último párrafo con una reflexión sobre la risa que magistralmente realiza Bajtín (1974): "La verdadera risa ambivalente y universal no excluye lo serio sino que lo purifica y lo completa. Lo purifica del dogmatismo, de unilateralidad, de esclerosis, de fanatismo y espíritu categórico, del miedo y la intimidación, del didactismo de la ingenuidad y de las ilusiones, de la nefasta fijación a un único nivel, y del agotamiento". Vale para mi inicio, y vale también para pensar que frente a la consagración de la idea de ciudadano, la potencialidad atractora de la ciudadanía como práctica destotalizada y destotalizante, de implicación posible entre iguales diferentes podrá ser, con toda seguridad, una nueva manera de afrontar los desafíos de construcción verdadera de derechos y deberes en el siglo XXI. Incluso con más alegría (cf. Frye, 1986).

\section{BIBLIOGRAFÍA}

Alonso, Luis Enrique (1999): Trabajo y ciudadanía, Trotta, Madrid.

Arendt, Hannah (1993): Entre pasado y futuro, Península, Barcelona.

Batjín, Mijail (1974): La cultura popular en la Edad Media y en el Renacimiento. El contexto de François Rabelais, Seix Barral, Barcelona.

Brecht, Bertolt (1978): Poemas y canciones, Alianza, Madrid.

Char, René (1964): Común presencia, Losada, Buenos Aires.

Esposito, Roberto (2003): Communitas, Amorrortu, Buenos Aires.

Freud, Sigmund (1981): El malestar en la cultura, Amorrortu, Buenos Aires.

Recibido: 25 de abril de 2009

Aceptado: 10 de junio de 2009
Frye, Northrop (1986): El camino crítico, Taurus, Madrid.
Frye, Northrop (2001): El gran código, Gedisa, Barcelona.

Goethe, Johann Wolfgang (1999): Poesía y verdad: de mi vida, Alba, Madrid.

Hume, David (1992): Tratado de la naturaleza humana, Tecnos, Madrid.

Huxley, Aldous (1980): Un mundo feliz, Plaza y Janes, Barcelona.

Lefort, Claude (1998): La invención democrática, Nueva Visión, Buenos Aires.

Marinas, José Miguel (2004): La fábula del bazar, Sintesis, Madrid.

Marramao, Giacommo (1993): "Paradojas del universalismo", en Revista Internacional de Filosofía Política, n. ${ }^{\circ}$, 7-20.

Orwell, George (1989): 1984, Destino, Barcelona. 